\title{
Pentetate Zinc Trisodium
}

National Cancer Institute

\section{Source}

National Cancer Institute. Pentetate Zinc Trisodium. NCI Thesaurus. Code C77835.

The trisodium salt form of zinc diethylene triamine pentaacetate (Zn-DTPA or pentetate zinc) with chelating activity. Upon administration, Zn-DTPA loses the Zn ion to form stable chelates with metal ions because DTPA has a higher affinity for heavy metal ions than for Zn ions. Specifically, this agent is able to bind to and form strong complexes with the radioactive plutonium, americium, and cerium after internal contamination. The formation of these heavy metal chelates enhances radionuclide excretion. 